\title{
La víctima y su resarcimiento en el sistema penal colombiano: Una mirada al incidente de reparación integral y a la demanda de parte civil $^{1}$
}

\section{The victim and his compensation in the Colombian penal system: a look at the incident and demand full compensation from civil part}

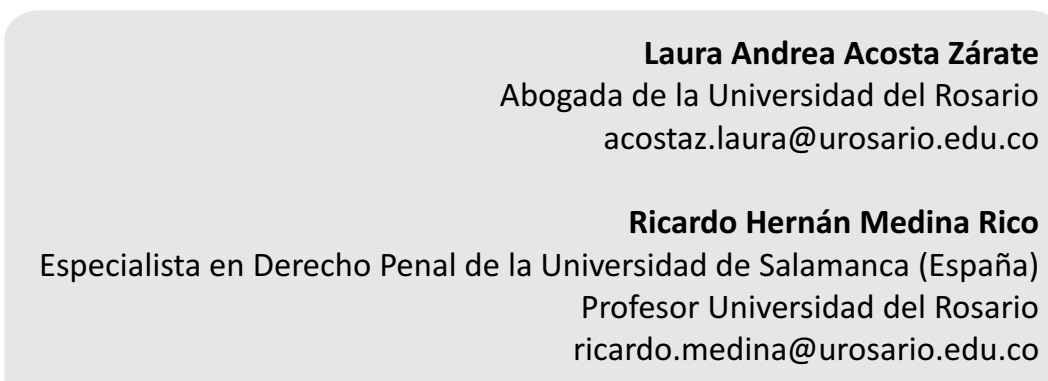

Recibido: 21/06/2014 Aprobado: 30/09/2014

RESUMEN

El presente artículo examina las figuras del incidente de reparación integral y la demanda de parte civil como mecanismos de acceso al resarcimiento de una víctima dentro del proceso penal, ya sea en la Ley 906 de 2004 o en la aún vigente Ley 600 de 2000. También es un estudio de las diferencias y similitudes entre ambas instituciones.

\section{PALABRAS CLAVE}

Daño, proceso penal, reparación, responsabilidad penal, víctimas.

\section{ABSTRACT}

The following document reviews the figures of incidental issue of redress and the civil claim as compensatory mechanisms for the victims among the criminal procedure, either with the law 906 of 2004 or the law 600 of 2000 which is still in force. As well is a study of the differences and similarities of both institutions.

\section{KEYWORDS}

Damage, criminal procedure, reparations, criminal liability, victims.

1.- El artículo es resultado de una investigación desarrollada en la línea de investigación "Problemas actuales del Derecho Penal" del Grupo de Investigación en Derecho Penal de la Universidad del Rosario. 


\section{INTRODUCCIÓN}

Cuando se halla de frente a la comisión de una conducta punible se descubren varios sujetos que, directa 0 indirectamente, son objeto de consecuencias dentro del ilícito. El autor o partícipe del delito será quien lleve sobre sus espaldas la pena como consecuencia jurídica de su actuar; mientras que, por su parte, la víctima será aquella sobre la cual recae un daño producido por la ejecución del delito.

Teniendo en cuenta lo mencionado, es apropiado resaltar que en un sistema penal como el vigente no sólo se debe plantear la simple retribución para el sujeto activo dentro del hecho reprochable, sino que se debe resarcir a la víctima examinando y consiguiendo su reparación completa y que se satisfagan las necesidades que nacieron con la comisión de la conducta antijurídica y culpable. Por ello, la víctima ha salido a relucir en los últimos años dentro del proceso penal. En la normativa vigente, encuentra consagración y amparo dicha figura a lo largo de la doctrina, la jurisprudencia y el ordenamiento positivo.

De cara a una viable solución del conflicto armado en Colombia, cabe preguntar ¿qué pasará con las víctimas en Colombia?, por lo cual, el texto a desarrollar busca solventar dudas frente al rol de la víctima en el proceso penal.

En virtud de lo anterior, este artículo se encuentra dividido en tres momentos, en primer lugar se expondrá el tema de las víctimas en Colombia, dónde se encuentra su protección y bajo el amparo de qué normas están. En segundo término se pasará a explicar las figuras de la demanda de parte civil y del incidente de reparación integral (a partir de semejanzas y diferencias de las mismas, enunciando brevemente su procedimiento y haciendo un análisis a partir de la norma escrita y del ordenamiento que las rigen); para por último presentar las conclusiones, teniendo en cuenta las similitudes y divergencias encontradas en las figuras en comento.

\section{LA VÍCTIMA SEGÚN LAS LEYES COLOMBIANAS VIGENTES}

En la Constitución Política de Colombia de 1991, se encuentra amparada la figura de las víctimas, estableciendo en el artículo 250 numeral 6 como un deber de la Fiscalía General de la Nación el brindar asistencia a las víctimas y "disponer el restablecimiento del derecho y la reparación integral de los afectados con el delito", de donde se colige una definición amplia según la cual víctima es toda persona afectada con el delito (CSJ Penal, 24 Nov. M. Gónzalez. No. 34933)

Por su parte, en la Ley 906 de 2004 - Código de Procedimiento Penal vigente - se encuentra expresamente el artículo 132, el cual expresa "Se entiende por víctimas, para efectos de este código, las personas naturales o jurídicas y demás sujetos de derechos que individual o colectivamente hayan sufrido algún daño (directo) como consecuencia del injusto (...)". En tanto al desarrollo jurisprudencial, la Corte Constitucional entiende a las víctimas como aquellas que "(...) son titulares de los derechos a la justicia, la verdad y la reparación las víctimas y perjudicados con el delito que hubiesen sufrido un daño real, concreto y específico, cualquiera que sea la naturaleza de éste" (CConst, C-516/2007)2.

Desarrollando lo expresado, el mismo tribunal señala:

Para acreditar la condición de víctima se requiere que haya un daño real, concreto y específico cualquiera que sea la naturaleza de éste, que legitime la participación de la víctima 0 de los perjudicados en el proceso penal para buscar la verdad y la justicia, el cual ha de ser apreciado por las autoridades judiciales en cada caso. Demostrada la calidad de víctima, o en general que la persona ha sufrido un daño real, concreto y específico, cualquiera sea la naturaleza de éste, está legitimada para constituirse en parte civil, y puede orientar su pretensión a obtener 
exclusivamente la realización de la justicia, y la búsqueda de la verdad, dejando de lado cualquier objetivo patrimonial (CConst, C-516/2007).

Ahora bien, en el ámbito internacional se expresa que:

Se entenderá por víctima a toda persona que haya sufrido daños individual o colectivamente, incluidas lesiones físicas o mentales, sufrimiento emocional, pérdidas económicas o menoscabo sustancial de sus derechos fundamentales, como consecuencia de acciones u omisiones que constituyan una violación manifiesta de las normas internacionales de derechos humanos o una violación grave del derecho internacional humanitario. Cuando corresponda, y en conformidad con el derecho interno, el término 'víctima' también comprenderá a la familia inmediata o a las personas a cargo de la víctima directa y a las personas que hayan sufrido daños al intervenir para prestar asistencia a las víctimas en peligro o para impedir la victimización (ONU. Res. No. 2005/35).

Por último, y no menos importante, debe señalarse que la Corte Suprema de Justicia, ha reiterado en sus providencias que según el artículo 132 de la Ley 906 de 2004, víctima es toda persona natural o jurídica que individual o colectivamente ha sufrido algún perjuicio como consecuencia del injusto, calidad que le otorga el derecho de acceder a la actuación e impone reconocerla como tal en el proceso. Sin embargo, los derechos a la verdad, la justicia y la reparación que habilitan tal intervención no son absolutos en cuanto se requiere la acreditación de un daño concreto, baremo que también se traslada al campo del ejercicio impugnatorio al ser necesario que quien promueva los recursos, además de tener legitimación en el proceso, dado el reconocimiento como interviniente o parte, tenga legitimación en la causa a través del interés jurídico para atacar la decisión si le ha irrogado algún perjuicio ${ }^{3 "}$.

\section{LOS DERECHOS DE LAS VÍCTIMAS. LA REPARACIÓN Y LAS FORMAS DE LLEGAR A ELLA}

Teniendo claro lo anterior, se debe en este instante señalar cuáles son los derechos de las víctimas en un sistema garantista como el que ampara el legislador en Colombia. Es de cotidiano reconocimiento que no basta con "causarle un daño al agresor" como método de retribución "Hammurabiana" para resarcir los perjuicios ocasionados, por el contrario, existen otros derechos que quizás son más importantes en la sociedad colombiana.

En la actualidad, los derechos de las víctimas de un delito son la verdad, la justicia y la reparación integral. Estos son derechos que se encuentran protegidos en el sistema penal con tendencia acusatoria instaurado mediante Acto Legislativo 03 de 2002 y desarrollado por la Ley 906 de 2004, modificada por la Ley 1395 de 2010, entre otras. Dicha protección no implica un traslado automático de todas las formas y esquemas de intervención en los que la víctima ejerció sus derechos ya que, en el anterior sistema procesal penal (regulado por la Ley 600 de 2000) ya se contemplaban mecanismos para reparar a la víctima (Londoño, 2008).

El ejercicio de los derechos anteriormente mencionados, deberá hacerse de manera compatible con los rasgos estructurales y las características esenciales del nuevo sistema procesal penal al que se ha hecho mención, así como la recordación constante de las definiciones que el propio constituyente adoptó al respecto; para lo cual, sería propio expresar la caracterización de las víctimas como intervinientes especiales a lo largo del proceso penal, no supeditadas al fiscal, sino en los términos que autónomamente fije el legislador.

En este punto, es preciso recalcar que la reparación de daños dentro del proceso penal, ya ha tenido larga trayectoria, tanto en la jurisprudencia como en la

3.- Ver. CSJ. PENAL 11 de Nov. 2009, Rad. 32564; CSJ. PENAL 6 Mar.2008, Rad. 28788 y Rad. 26703; CSJ. PENAL 1 Nov. 2007, Rad. 26077; CSJ. PENAL 10 Ago. 2006, Rad. 22289. 
norma; ello, con el objetivo de imponer la obligación de restituir e indemnizar a la víctima, en el marco del proceso penal como medio válido para concretar y conseguir la reparación de daños y perjuicios ocasionados con el delito (CSJ Penal. 20 Sept.1982).

Ahora bien, con respecto a las figuras que se pretenden estudiar en este artículo, es necesario entender la diferencia que existe entre una demanda civil - vista como el ejercicio del derecho de acción -y la naturaleza propia de un incidente, ya que la acción doctrinariamente ha sido entendida como el "derecho público subjetivo que tiene todo sujeto de derecho, de acudir a los órganos jurisdiccionales para reclamarles la satisfacción de una pretensión mediante un proceso" (López Blanco, 2003:280); por otra parte, el incidente podría definirse como un trámite de audiencias, con características de procedimiento civil, pero trámite de juicio penal, por medio del cual se plantea resarcir de manera íntegra los daños causados por la comisión del delito y que no se hayan satisfecho con anterioridad; teniendo en cuenta la necesidad de demostración del vínculo existente entre el daño, el ya declarado responsable penalmente y la víctima que debe acreditarse durante el trámite. Del incidente debe mencionarse que rompe "o con el paradigma de la justicia retributiva, la Ley 906 de 2004 acogió como se dijo en precedencia los postulados de la Justicia restaurativa, como fórmula efectiva y positiva para la solución de conflictos derivados del delito, la víctima dentro de este esquema interviene en el proceso penal"(Avellaneda y Arguello. 2011).

En la Ley 600 del 2000, la reparación del daño ocasionado por el delito tiene como finalidad como lo ha señalado la Corte Constitucional dejar a la víctima y a los perjudicados por el hecho punible en la situación más próxima a la que existía antes de la ocurrencia del mismo (CConst, C-916/2002). En ese orden de ideas, con respecto a la Ley 600 de 2000, la indemnización de perjuicios se reguló dentro del proceso penal, basado en lo siguiente: i. La reparación de la conducta punible incluye los daños materiales y morales y se refiere tanto a daños individuales como colectivos.

ii. La liquidación de los perjuicios ocasionados por el delito debe hacerse de acuerdo con lo acreditado en el proceso penal (Art. 42).

iii. La indemnización integral de los perjuicios ocasionados para ciertos delitos, trae como consecuencia la extinción de la acción penal.

iv. La regulación de medidas para garantizar la indemnización integral, de tal manera que el juez penal podrá no solo disponer en la sentencia condenatoria el remate de bienes decomisados, sino en el curso del proceso adoptar medidas sobre bienes del procesado ${ }^{4}$.

v. La determinación de los obligados, de tal forma que el juez penal podrá llamar a quienes, según la ley sustancial, estén obligados a responder solidariamente. (Art. 46)

vi. Cuando no es posible la determinación objetiva de los perjuicios, se acude a los criterios que establece el Código Penal (Art. 56).

vii. La solicitud de la reparación ante la jurisdicción civil, excluye la posibilidad de acudir a la jurisdicción penal para reclamar la reparación de los perjuicios (Art. 52).

viii. La obtención del beneficio de suspensión condicional de la ejecución de la pena, puede ser supeditada a que se efectúe la reparación integral de los perjuicios

ix. En la sentencia condenatoria debe incluirse la condena en perjuicios cuya existencia haya sido demostrada en juicio, a menos que exista prueba de que se promovió de manera independiente la acción civil de indemnización (Navarro, 2009).

Por otra parte, con el proceso acusatorio se amplía el espectro y alcance de la reparación, desde el punto de vista de los derechos de las víctimas, que a diferencia del estatuto penal anterior, se centraba únicamente en la indemnización material y moral. Con la Ley 906 del 2004 se le dan más atribuciones y derechos a la víctima. Por eso, la reparación se

4.- Así, en el artículo 50 de la Ley 600 de 2000, postula la admisión de la demanda y facultades de la parte civil. 
muestra como una hipótesis de justicia restaurativa, donde: "El Estado tiene... un interés en que el daño sea resarcido del modo más rápido posible." (Navarro 2009). Se abre campo, de igual manera, a brindarle a la víctima, un conjunto de beneficios durante el trámite del incidente de reparación, tales como el postulado en el artículo 136 de la L.906/04, que habla sobre el Derecho a recibir información. (Navarro 2009).

Así, la Ley 906/04, postula a tres partes como titulares, los cuales podrán interponer el incidente de reparación integral, en un término de 30 días desde el anuncio del fallo de responsabilidad penal. Estas partes son: Víctima, Fiscalía y Ministerio Público (Navarro 2009). Lo anterior se ha modificado, ya que no necesitamos tan solo el anuncio del fallo de responsabilidad como menciona el autor Navarro, sino que, en la actualidad, se requiere una sentencia condenatoria ${ }^{5}$.

De igual forma, es fundamental entender el cambio jurisprudencial que tuvo lugar en vigencia de la Ley 600 del 2000, dado que la Corte Constitucional en Sentencia C-1149 del 2001, consideraba que la naturaleza de la acción civil dentro del proceso penal era netamente indemnizatoria, y su única y exclusiva finalidad sería el restablecimiento del derecho y el resarcimiento de todos los daños ocasionados como consecuencia de la comisión de un acto delictivo; lo anterior daba lugar a que no se tuvieran en cuenta otro tipo de daños.

En el año 2002, la Corte Constitucional cambio su línea jurisprudencial respecto a este tema, estableciendo en la sentencia C-228, que los derechos de las víctimas y de los perjudicados por un delito, no se encontraban circunscritos a la reparación material sin que se orientara a su restablecimiento integral.

Es preciso mencionar que la posición de la víctima frente al proceso en cada uno de los sistemas es completamente diferente, ya que en los términos de la Ley 600 de 2000, la vinculación del tercero civilmente responsable podía solicitarse desde la admisión de la demanda de parte civil, o incluso antes de proferirse la providencia de cierre de la investigación, reconociéndosele, de conformidad con el artículo 141 de la citada Ley, los mismos derechos y facultades de cualquier sujeto procesal.

Como menciona el Supremo Constitucional, mediante el Acto Legislativo 03 de 2002 y la Ley 906 de 04 se avanzó hacia un sistema de investigación y juzgamiento penal de marcada tendencia acusatoria, que introduce un nuevo enfoque respecto de los actores que integran la relación jurídico-procesal, previendo expresamente la intervención en el proceso de: (i) las víctimas; (ii) el imputado; (iii) el fiscal; (iv) el juez de conocimiento; (v) el Ministerio Público; (vi) el juez de control de garantías. Tales modificaciones incidieron en la regulación legal del tema bajo examen: al (i) desaparecer la parte civil; (ii) al dejar el tercero civilmente responsable de ser sujeto procesal; (iii) al permitirse durante la etapa de investigación la imposición de una medida cautelar consistente en la entrega provisional del vehículo, nave 0 aeronave, para el caso de los delitos culposos; y (iv) al establecer un incidente de reparación integral, el cual se lleva a cabo con posteridad al fallo condenatorio y previa solicitud expresa de la víctima, del fiscal o del Ministerio Público, durante el cual es citado quien debe responder por el hecho ajeno (CConst, C-250/2011).

De lo anterior, es posible evidenciar que existe un gran número de diferencias entre el incidente de reparación integral y la demanda de parte civil. En cuanto a su procedencia y ejercicio:

- En la Ley 906 de 2004, una vez emitido el fallo de culpabilidad puede tener lugar el incidente de reparación integral, el que tiene por objeto la reparación de los daños causados a la víctima con la conducta criminal. Se enmarca en los derechos esenciales de la misma a obtener justicia, verdad y reparación, por lo cual tiene

5.- Así, en el artículo 50 de la Ley 600 de 2000, postula la admisión de la demanda y facultades de la parte civil. 
arraigo constitucional y su desarrollo legal está en los artículos 102 y siguientes de la Ley 906 de 2004.

- Están legitimados para presentar la pretensión de reparación integral la víctima, sus herederos, sucesores o causahabientes, cuando la reparación tiene exclusivamente carácter económico. Si es de otra naturaleza podrán hacerlo el fiscal o el ministerio público, por solicitud de la víctima.

- Por el contrario en la Ley 600 de 2000, la demanda de parte civil podría presentarse ante la jurisdicción civil o penal y se podía intentar la constitución como parte civil en cualquier momento, a partir de la resolución de apertura de instrucción mediante la presentación de la demanda de parte civil o incluso antes de proferirse la providencia de cierre de la investigación.

Por otra parte, en cuanto al trámite de cada uno de los procedimientos de reparación de victima en cada uno de los sistemas tenemos grandes diferencias, bajo el sistema penal acusatorio, en la primera audiencia de trámite el incidentante formula su pretensión oralmente e indica las pruebas que hará valer. El juez examina la admisibilidad de la pretensión y tiene dos opciones para resolver: (i) la rechaza por falta de legitimación, o por pago efectivo de los perjuicios, si la pretensión fuere solamente económica; o (ii) la admite. Aceptada la pretensión, el juez la pone en conocimiento del declarado penalmente responsable, ofrece a las partes la posibilidad de conciliación que, de prosperar, pone fin al incidente (Ochoa y Otros, 2005).

En caso contrario, el juez convoca a los intervinientes a una nueva audiencia, dentro de los ocho días siguientes, para intentarla una vez más, con la advertencia al culpable, que en esta nueva oportunidad debe ofrecer sus medios de prueba con los que se proponga oponerse a las pretensiones de la víctima, caso en el cual, dispone la práctica de las pruebas ofrecidas por cada parte y después de escuchar el argumento de sus pretensiones, adopta la decisión que pone fin al incidente, que debe ser incorporada a la sentencia.

La inasistencia injustificada del solicitante a cualquiera de las audiencias, primera de trámite, de pruebas o alegaciones, se entiende como desistimiento de la pretensión y genera el archivo de la solicitud y condena en costas.

Si no comparece injustificadamente el declarado penalmente responsable, el juez dispone la práctica de la prueba ofrecida por el incidentante $y$, con base en ella, adopta la decisión que corresponda. En cualquier caso quien no comparece queda vinculado a los resultados de la decisión 6 .

Por su parte, en el modelo de la Ley 600 de 2000 , el esquema de parte civil es completamente diferente, el trámite establecido es el siguiente:

Dentro de los tres (3) días siguientes a aquél en que se presente el escrito de demanda, el funcionario judicial que conoce del proceso decidirá mediante providencia interlocutoria sobre su admisión o rechazo. La providencia que resuelve sobre la demanda de parte civil es apelable en el efecto devolutivo. Admitida la demanda de parte civil, ésta quedará facultada para solicitar la práctica de pruebas orientadas a demostrar la existencia de la conducta investigada, la identidad de los autores o partícipes, su responsabilidad, y la naturaleza y cuantía de los perjuicios ocasionados. Podrá igualmente denunciar bienes del procesado y solicitar su embargo y secuestro, e interponer recursos contra las providencias que resuelvan sobre las materias. La demanda será rechazada cuando esté acreditado que se ha promovido independientemente la acción civil por el mismo demandante, que se ha hecho efectivo el pago de los perjuicios, que se ha producido la reparación del daño o que quien la promueve no es el perjudicado directo.

También procede el rechazo cuando la demanda se dirija contra el tercero civilmente responsable y la acción civil se encuentre prescrita. En cualquier 
momento del proceso, en que se acredite cualquiera de las situaciones descritas, mediante providencia interlocutoria se dará por terminada la actuación civil dentro del proceso penal. La acción civil, dentro del proceso penal, se adelantará en cuaderno separado en el que se allegarán todas las pruebas y actuaciones relacionadas con la pretensión patrimonial.

Por último, es importante tener en cuenta que los artículo 86 y 89 de la Ley 1395 de 2010, modificatorios de los artículos 102 y 106 de la Ley 906 de 2004 prevén la procedencia y ejercicio del incidente de reparación integral, una vez en firme la sentencia condenatoria, y precisa el término de caducidad para la solicitud de reparación integral a los treinta (30) días después de haber quedado en firme el fallo condenatorio. Según la Corte:

(...) no se vulneran los derechos del tercero civilmente responsable, ya que dichas disposiciones no entrañan limitación a los derechos de participación en las decisiones del tercero civilmente responsable, puesto que el derecho a su participación dentro del proceso penal será constitucionalmente legítima únicamente a partir del momento en que se ha determinado la responsabilidad penal del sujeto por el cual deberá responder civilmente, momento que surge necesariamente - después de encontrarse en firme la sentencia de condena con la iniciación del incidente de reparación integral y su citación al mismo, en el que contará con todos los derechos y garantías tendientes a su participación activa y a la construcción de la decisión que lleve a su culminación. Asimismo, al ser citado el tercero civilmente responsable al incidente de reparación integral, cuenta con todas las garantías de acceso a la justicia, con la posibilidad de debatir, dentro del incidente, la existencia o no del perjuicio y el monto de la reparación; a objetar las pretensiones de la víctima, así como su relación para con el condenado y su deber de reparación; a solicitar la citación al asegurador; a participar en las audiencias; a conciliar y a interponer los recursos a que haya lugar, en desarrollo de los postulados establecidos en los artículos 102 y ss. del CPP. En cuanto a la caducidad de la solicitud de reparación integral treinta (30) días después de haber quedado en firme la sentencia de condena, tampoco se vulnera el derecho del tercero civilmente responsable a la participación en las decisiones que le afectan y a la tutela judicial efectiva, ya que si bien, en desarrollo de la libertad de configuración legislativa el legislador estableció dicho término con el fin de racionalizar los procedimientos judiciales e imprimirles seguridad jurídica, el límite se considera válido pues establecida la constitucionalidad del papel del tercero civilmente responsable circunscrito a la etapa del incidente de reparación integral, la norma acusada busca la celeridad en los procesos judiciales, sin menoscabo de los derechos de partes e intervinientes (CConst, C250/2011).

En concordancia a todo lo anteriormente mencionado y a partir de una comparación de lo tipificado en ambas legislaciones, es preciso anotar que lo contemplado en la Ley 600 de 2000 y en la Ley 906 de 2004 en cuanto a la reparación de víctimas tiene ciertas semejanzas pero grandes diferencias.

En cuanto a las similitudes se evidencia:

- Tanto la demanda de parte civil como el incidente de reparación integral encuentran su fundamento en el Código Penal, Artículo 94, que establece la obligación que nace de toda conducta punible para reparar los daños materiales y morales causados con ocasión de la conducta.

- El mismo Código Penal estableció que son titulares de la acción civil las personas naturales, sus sucesores y también las personas jurídicas perjudicadas directamente por la conducta punible.

- La obligación de indemnizar se encuentra en cabeza de los penalmente responsables en forma solidaria, sumándose otros terceros que puedan llegar a estar obligados a responder.

- La tasación de la indemnización de perjuicios, en cualquiera de los dos procedimientos, podrá 
ascender hasta a 1000 SMLMV, teniendo en cuenta la naturaleza de la conducta y la magnitud del daño causado.

- Ambas acciones son de carácter rogado, es decir se requiere el interés de los perjudicados para iniciar la demanda de acción civil y la acción de reparación integral.

- En ambos eventos hay lugar al rechazo de las pretensiones. En la acción civil, la demanda puede ser rechazada en caso de que la acción civil se haya promovido de forma independiente al proceso penal, o si se demuestra la reparación del daño o la falta de interés al no ser el perjudicado directo. En el incidente de reparación integral se rechazara por las mismas causas cuando se demuestre que no es víctima quien la promueve o que se ha acreditado el pago de los perjuicios.

- Es posible que las personas perjudicadas se constituyan en parte civil de forma separada 0 conjunta, lo mismo ocurre en el incidente de reparación integral en donde las víctimas podrían presentar sus pretensiones en forma conjunta, como en el caso de sucesores que acumulen sus pretensiones teniendo en cuenta que comparten la misma calidad.

- Si bien el trámite es distinto en ambos casos es posible vincular a los terceros civilmente responsables al proceso.

En contraste, las divergencias conceptuales, técnicas y de fondo que se encuentran entre las dos instituciones sujetas a estudio son:

Con respecto a la demanda de parte civil:

- Para poder restablecer el derecho y resarcir el daño es necesario que el perjudicado y sus sucesores se constituyan como parte civil dentro de la actuación penal, siempre a través de abogado. Es decir que es necesaria la solicitud rogada de la víctima pero mediante representación.

- La acción civil puede ejercerse dentro de la jurisdicción civil o también dentro del mismo proceso penal a elección de los interesados. Esta constitución como parte civil puede intentarse en cualquier momento dentro del proceso penal o paralelo al mismo en la jurisdicción civil; lo que implica que no necesariamente debe haber una sentencia condenatoria en firme.

- El trámite de constitución de la parte civil comienza con la presentación de la demanda de constitución que establezca los lineamientos generales de la indemnización; como la identificación del perjudicado, de los presuntos responsables, los hechos generadores de los daños y perjuicios y los mismos de orden material y moral estimando la cuantía y las medidas para el resarcimiento.

- Las pruebas que se pretendan hacer valer deberán ser presentadas junto con la demanda de la parte civil.

- Las formas de notificación de admisión de la demanda de la parte civil incluyen la notificación personal al demandado así como el emplazamiento en caso de que no se pueda surtir la notificación personal. En este caso no hay lugar a la conciliación para poner fin a la acción civil.

- La demanda se admite o rechaza dentro de los 3 días siguientes a la presentación de la misma, decisión mediante auto interlocutorio que se puede apelar en el efecto suspensivo.

- Una vez admitida la demanda se deberá solicitar la práctica de pruebas para demostrar los perjuicios y su naturaleza, así mismo habría lugar a solicitar embargo y secuestro de bienes del procesado.

- Si bien la demanda de la parte civil se maneja en cuaderno aparte paralelo al proceso penal, la decisión definitiva respecto de la misma tiene lugar dentro de la sentencia condenatoria que se profiere al final del proceso penal.

- Es posible vincular a un tercero civilmente responsable en la misma demanda de constitución de parte civil o de forma posterior a esta, mediante escrito separado que cumpla con los requisitos de la demanda de la parte civil.

De manera correlativa, en el incidente de reparación:

- Se requiere previa solicitud expresa de la víctima, 
del Fiscal o del Ministerio Público en representación de la misma. En este caso, la víctima lo puede llevar a cabo directamente y no requiere representación a través de abogado.

- El incidente de Reparación Integral se resuelve en audiencia pública, que será convocada por el juez fallador dentro de los 8 días siguientes a la solicitud presentada.

- La sentencia condenatoria debe necesariamente estar en firme al momento de solicitar la reparación integral; lo cual implica que no haya lugar a recursos en contra del fallo definitivo. (Con anterioridad sólo se requería el sentido del fallo y que éste declarara la responsabilidad penal del acusado).

- El trámite del incidente de reparación integral se llevará a cabo mediante audiencia en donde la pretensión será formulada verbalmente, incluyendo la forma de reparación integral a la que se aspira y la indicación de las pruebas a hacer valer.

- En este caso no se trata de la persona demandada, sino de la persona condenada como penalmente responsable de la conducta punible, quien deberá entrar a responder por los perjuicios causados.

- Una vez se admite la pretensión se pone en conocimiento del condenado y se ofrece la posibilidad de las partes de una conciliación que podrá poner fin al incidente. En caso de que no haya conciliación se citará a una nueva audiencia dentro de los ocho días siguientes para intentar la conciliación nuevamente.

- En caso de no lograrse la conciliación en la segunda audiencia se procede con el ofrecimiento de los medios de prueba del sentenciado. En esta audiencia se llevará a cabo entonces la práctica de la prueba y habrá lugar a que ambas partes hagan las correspondientes alegaciones.

- La decisión de la reparación integral se tomará en la misma audiencia mediante sentencia, lo que es diferente en el caso de la Ley 600 teniendo en cuenta que en ese caso no ha habido sentencia de condena y por ende la acción civil se decide en conjunto con la condena.
- En este caso hay además caducidad de la acción, teniendo en cuenta que la solicitud de reparación se deberá presentar dentro de los 30 días siguientes a que quede en firme el fallo condenatorio.

- En este caso también es posible vincular al tercero civilmente responsable, pero no mediante la demanda de la parte civil, sino que este podrá ser citado al incidente a solicitud de la víctima o el defensor del condenado, dentro de la audiencia que abra trámite al incidente. Frente a lo anterior, la Corte Constitucional ha dicho que el tercero civilmente responsable también tiene garantías frente al derecho de defensa en relación con el decreto y la práctica de medidas cautelares en su contra, en caso de que la vinculación que haga con anterioridad a la audiencia de incidente de reparación.

- En el incidente hay mención expresa respecto de la viabilidad de citar al asegurador, quien deberá participar dentro del curso de incidente y en caso tal demostrar que la inexistencia de obligación de indemnizar a las víctimas.

\section{CONCLUSIONES}

El Derecho penal del siglo XXI no se completa con el simple "castigo" que se le debe aplicar a quien comete un delito.

Las víctimas han tomado especial importancia dentro de un proceso penal, reconociéndoles sus derechos a la verdad, la justicia y la reparación.

La legislación colombiana siempre se ha encontrado acompasada con los derechos de las víctimas, por ello ha contemplado figuras como la demanda de parte civil y el incidente de reparación integral para conseguir que la víctima sea resarcida en el daño que se le haya ocasionado.

Estas figuras, de legislaciones distintas y procedimientos penales disímiles, tienen un primigenio fin similar, y es resarcir el daño causado a la víctima. 
Tienen diferencias de fondo, ya que los trámites son distintos además de que, en la Ley 600 el trámite era paralelo al proceso penal, mientras que el la ley 906 el incidente comienza sólo a partir de la condena del acusado.

Con el incidente de reparación integral se ha trascendido más allá del simple resarcimiento económico, y se han logrado otros mecanismos de reparación al ofendido.

\section{REFERENCIAS BIBLIOGRAFÍCAS}

- Avellaneda, L. \& Arguello, L. (2011). La víctima y el trámite de incidente de reparación integral en el nuevo sistema penal acusatorio como presupuesto de aproximación a la justicia restaurativa. En la Revista Verba luris - Estudiantil Vol. 1

- Bernate Ochoa, F. (2005) Sistema Penal Acusatorio. Universidad del Rosario. Bogotá (Colombia).

- Gaviria Londoño, V. (2008). Víctimas, acción civil y sistema acusatorio, Universidad Externado de Colombia, 2da Edición, Bogotá (Colombia).

- López Blanco, H. (2012). Instituciones de Derecho Procesal Civil Colombiano. Tomo 1. Editorial Dupre

- Navarro, A. (2009). La justicia restaurativa y el incidente de reparación. Bogotá D.C. Leyer.
JURISPRUDENCIALES

- CConst. C-516/2007, J. Córdoba.

- CConst. C-250/2011, M. González.

- CConst. C -370/2006, M. Cepeda; J. Córdoba; R. Escobar; M. Monroy. Á. Tafur; C.Vargas.

- CConst. C-578/2002. M. Cepeda.

- CConst. C-916/2002. M. Cepeda.

- CConst. C-228/2002. M. Cepeda;E. Montealegre.

- CSJ Penal, 11 Nov.2009, Rad. 32564. J. Socha.

- CSJ Penal, 6 de marzo de 2008, Rad. 28788. Y. Ramírez.

- CSJ Penal, 6 de marzo de 2008, Rad. 26703. S. Espinosa.

- CSJ Penal, 1 de noviembre de 2007, Rad. 26077. S. Espinosa.

- CSJ Penal, 10 de agosto de 2006, Rad. 22289. M. Pulido.

- CSJ Penal, 24 Nov. 2010, Proceso No. 34993 M. González.

- CSJ Penal, 20 Sept.1982. G. Gómez.

\section{NORMATIVA}

- Constitución Política de Colombia

- L.600/2000

- L.906/2004

- Principios y Directrices Básicos sobre el Derecho de las Víctimas de Violaciones Graves de los Derechos Humanos y las Libertades, adoptados por la Comisión de Derechos Humanos de la ONU por Resolución No. 2005/35. 